\title{
How CAPE tools can contribute to process sustainability
}

\author{
B. Kalitventzeff ${ }^{\mathrm{a}, *}$, G. Heyen ${ }^{\text {ab }}$, H. Closon ${ }^{\mathrm{a}}$, B. Vrielynck ${ }^{\mathrm{a}}$, F. Marechal ${ }^{\mathrm{c}}$ \\ ${ }^{a}$ Belsim S.A., Rue Georges Berotte, 29, B-4470 Saint-Georges-sur-Meuse, Belgium \\ ${ }^{\mathrm{b}}$ LASSC, Université de Liège, Sart Tilman B6a, B-4000 Liège, Belgium \\ ${ }^{c}$ Laboratory of Industrial Energy Systems, Swiss Federal Institute of Technology, CH-1015 Lausanne, Switzerland
}

Received 30 July 2002; accepted 5 December 2002

\begin{abstract}
The concern of the EFCE for sustainability. Four recent case studies to illustrate how CAPE tools contribute to process sustainability: (1) ultimate plant operation at Wacker-Chemie (DE), (2) development of a new sulphuric acid plant with Air Liquide (FR), (3) plant retrofit for $\mathrm{CO}_{2}$ abatement at Kemira (BE), (4) insertion of a new plant in an existing Solvay industrial site (Asia). (C) 2003 Published by Elsevier Ltd.

Keywords: Computer Aided Process Engineering (CAPE); Minimum Energy Requirement (MER); Industrial applications; Process integration; Data reconciliation; Acetylacetone plant; Ammonia plant; Sulphuric acid; $\mathrm{CO}_{2}$ abatement; Site wide energy integration
\end{abstract}

\section{The concern for sustainability}

The EFCE (European Federation of Chemical Engineering) is at present aiming to contribute to the general European Union concern for sustainability. What can the Federation do? How can its working parties contribute to this effort? For those who are active in CAPE, as we are, how can they contribute?

We often learn about "sustainable technologies", we question their importance, would we not preferably have to speak about "sustainable processes"? What has to be sustainable? Our products and our production means, have to answer the societal needs in the broad sense; it is not only a matter of taking the environment in consideration by reducing emissions.

Engineers active in the chemical process industry are aware, or will have to be aware of the broader concept of the development of a sustainable global system. However we will restrict ourselves here to some examples of what can be done to enhance process sustainability.

If process sustainability appears at first sight to be adding more and more stringent constraints in a more

\footnotetext{
* Corresponding author. Tel.: +32 425988 88; Fax: +32 4259 8889.

E-mail addresses: boris.kalitventzeff@belsim.com (B. Kalitventzeff); g.heyen@ulg.ac.be (G. Heyen); francois.marechal@epfl.ch (F. Marechal).
}

and more restrictive time frame, new CAPE tools are today available to support the process engineer's creativity allowing them elaborate innovative solutions. Innovation is not only a matter of intuition, innovative methods exist and are developed to generate alternatives for existing plant renovation or for new plant design (e.g. EASY, Energy Analysis and SYnthesis tool of Belsim S.A.). Even if the process engineering experience will probably remain essential, it will be supplemented by advanced methods combining the use of relational data base, modelling, operation research, expert systems, graphical representation and web based information technology, that today show promising results (e.g. EXSYS, the expert system of the University of Liege for the insertion of Intensified Energy Saving Technologies (IEST) in the chemical processes (Kalitventzeff and Marechal [1]).

We would like to support the reference to snapshot expressions like the 3E-3R formula:

$3 \mathrm{E}$ $3 \mathrm{R}$

$\begin{array}{ll}\text { - Energy } & \text { - Reduce } \\ \text { - Environment } & \text { - Recycle } \\ \text { - Economics } & - \text { Reuse }\end{array}$


Below we report our experience of this $3 \mathrm{E}-3 \mathrm{R}$ formula. It is a good formula to keep in mind when aiming at better quality in process management, an essential part of process sustainability. Neither all 3E nor all 3R will be present in every process improvement objective, but most of these should be.

The needs are not only the state of the art of the socalled Best Available Technologies (actual status of the technology and its expected performances), but also the conditions of their integration in the process under study. We prefer the concept of Most Suitable Technologies for the integrated system. These are numerous, process integration, energy technologies, combined heat, power and utilities (water, refrigeration, $\mathrm{H}_{2}, \mathrm{O}_{2}, \ldots$ ), waste treatment and recycling, water and other resources, process intensification, and integration between processes.

In the following, we will illustrate the benefits of the CAPE tools. Our purpose is not to demonstrate a wonderful, magic engineering suite but to illustrate how CAPE tools can contribute to the sustainable development of industrial process by sharing our experience on some industrial projects that the authors have conducted. From a methodological point of view, we would like to insist on the real role of CAPE tools as a catalyst in the process development procedure but also on the importance of the competence of the CAPE tools users and the way they have to communicate with the team of process developers. As mentioned in Marechal [2], the CAPE tools utilisation methodology takes place in three steps: AGE (Analyse - Generate - Evaluate). The first step is the problem analysis and statement, coding a problem into a suitable form for using CAPE tools; the second step corresponds to the production of numerical results using CAPE tools; the evaluation step is the transformation of the results into useful engineering solutions to finally produce process solutions.

\section{Belsim engineering services help to upgrade the Wacker-Chemie Acetyl Acetone plant capacity by $14 \%$}

Wacker-Chemie (Germany) has a lasting history of cooperation with Belsim S.A. This company produces chemicals with high added value for which they have to obtain the yearly authorisation to produce. For more than 10 years, they have used VALI, a software tool of Belsim S.A. for data reconciliation or validation. Initially, this was limited to mass balance, off line applications, and now on line monitoring for complex plants, this has become a part of their quality process management, they use it to obtain the necessary certification from the public control authorities.

Quality process management includes, of course, the concerns of performance follow-up of equipment, of tracking inaccurate measurements and of generating more information from the available redundant measurements and lab analyses. This is managed already in the control rooms.

Validation reports are further exploited for process knowledge improvement. In particular sensitivity analyses with VALI indicate the most influential data and the most influential equipment.

Wacker-Chemie has published the economic results obtained by using VALI, for instance, the reduction by $50 \%$ of the lab measurements cost needed for plant follow-up.

Wacker-Chemie allowed Belsim S.A. to report on the following co-operation, which can be regarded as a good example (in our opinion) of the "ultimate plant operation" objective. Once the plant knowledge becomes better and better the process manager wants to check how to modify its plant to perform even better.

Wacker-Chemie is a major producer of acetylacetone (ACAC), and owns several patents on processes to produce it. This chemical is produced by isomerisation of isopropenylacetate (IPA). The company goal was to increase its production capacity, and a new reactor was designed. The previous design heated IPA vapour in a coil located in an electrically heated furnace (Fig. 1). The reactor exhaust was immediately quenched to avoid excessive product degradation, leading to coke deposition and off gases formation. For the original reactor operation, coke formation was such that the plant had to be shut down for tube cleaning after a few weeks of operation. Belsim S.A. was asked to optimise the design of a new reactor (Fig. 2), in which a series of tubes could be heated individually by Joule effect. The desired temperature profile was to be controlled by proper adjustment of the electrical current in each tube section. No detailed reaction model was available, and even the physical properties of some components were uncertain.

Test run data was collected for half a dozen typical operating conditions, covering a range of residence time and specific energy flow in the reactor; measurements were the feed and product flow rates and composition, temperature at the coil outlet, electrical power dissipated

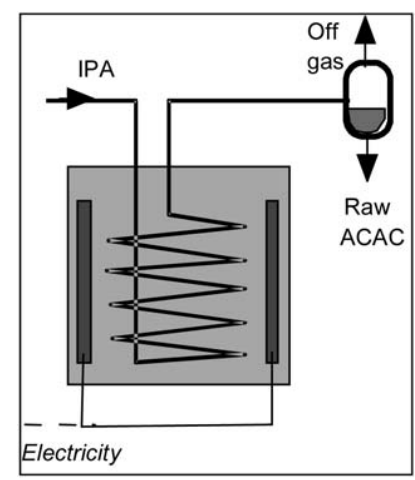

Fig. 1. Original reactor design. 


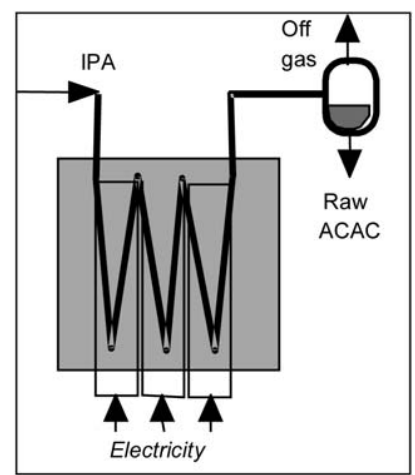

Fig. 2. New design, as proposed initially.

in the furnace. Energy and component mass balance constraints were used to validate all available measurements, this was important, since some measured data were not very precise, being obtained from the existing instrumentation. A detailed simulation model, involving mass and momentum balance, convective and radiative heat transfer coupled with chemical reaction was developed. This allowed fitting of a kinetic model and to identification of some physical properties of the reactive mixture.

Next, optimisation of the temperature profile was attempted. It revealed that the assumed mode of operation was improper. The isomerisation reaction is exothermic, and its activation energy is smaller than that of the side reactions. Excessive heating of the reaction mixture was thus to be avoided. The reactor design was changed, a pre-heater was used to bring the mixture to a temperature high enough for the main reaction to start, but low enough to avoid significant product degradation. Reaction itself was allowed to take place in an almost isothermal section, where heat losses through the insulation correspond roughly to the heat of reaction. The volume of this reaction section was optimised to achieve the highest selectivity (Fig. 3).

A novel procedure to control the energy required in the pre-heater was identified, by monitoring the optimal temperature profile in the reactor.

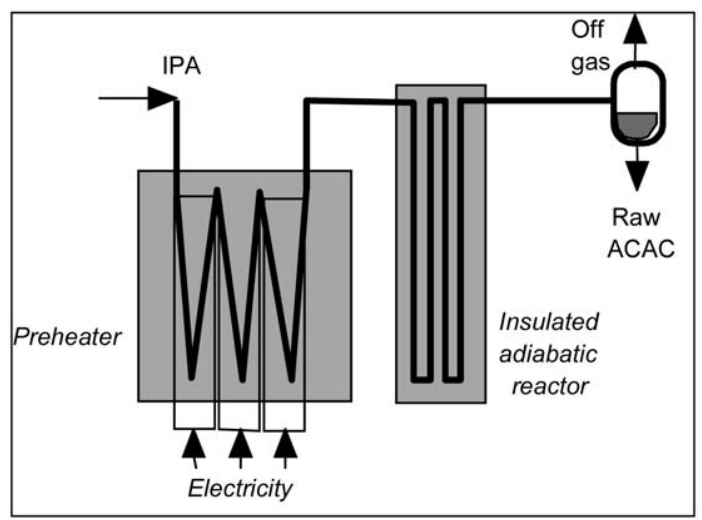

Fig. 3. New design, as optimised.
The results were:

- $14 \%$ productivity improvement of the ACAC plant for similar feed flow rate.

- Significant reduction of the plant variability, due to an easier control.

- Drastic reduction of coke formation, thus allowing to operate the plant for more than four months without cleaning.

- $20 \%$ reduction of specific energy consumption.

- New patent for a old, well known process (Dempf et al. [3]).

- Dynamic model of the process that is now also used for operator training.

The benefit for the company was manyfold:

- Increased knowledge about a process, thus better control of its operation.

- Limited cost due to subcontracting to modelling specialist (each partner only acts in its core business).

- Better and faster response to the market demand.

- Limited consumption of energy and reduction of production wastes.

- Cleaner operation, lowering the burden on the operators and the maintenance personal.

\section{Insertion of an Intensified Energy Saving Technology (IEST) leads to a newly patented $\mathrm{H}_{2} \mathrm{SO}_{4}$ plant}

As a second example, we report on a new Sulphuric Acid plant recently patented by Air Liquide (Arpentinier et al. [4]), a design which was started by a VALI data reconciliation of an existing plant, the insertion of an IEST (technical low grade oxygen) in the existing plant to increase the $\mathrm{SO} 2$ conversion (an alternative to the double-contact/double-absorption process); several alternatives were examined.

Thorough analysis of the software results did highlight the potential opportunity of recycling the outlet of the single absorption tower to the Sulphur furnace, after a purge to avoid accumulation in the new global cycle process. A new process was born; it had to mature through energy integration, modification of the absorption tower, and process intensification (elimination of air drying tower, smaller air blower, etc.) (Fig. 4).

The main advantages of this new process concept (tail gas recycling coupled with oxygen feed) with respect to the double-contact/double-absorption process are:

1. Process intensification/lower capital investment (no drying tower, smaller air blower as recycling blower, only one absorber, $60 \%$ less catalyst required and thus smaller catalytic reactor); 


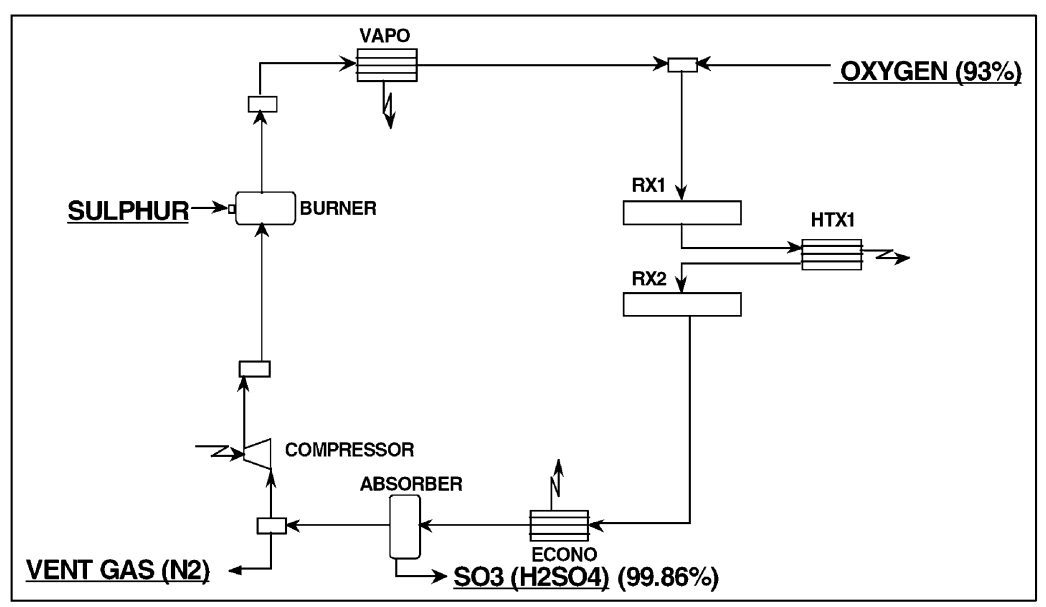

Fig. 4. Modified new process structure.

2. $10 \%$ more mechanical energy recovered which is used for the oxygen production;

3. Reduced environment impact: sulphur conversion $>99.6$ mole\% ( $\left.1 \mathrm{~kg} \mathrm{SO} / \mathrm{t} \mathrm{H}_{2} \mathrm{SO}_{4}\right)$, oxygen conversion $>98$ mole $\%$.

Finally the global economic balance difference is $8.3 \%$ in favour of the new process, not taking future emission taxes into account. An extrapolation at the European level indicates a potential reduction of the annual $\mathrm{SO}_{2}$ emissions to the atmosphere of approximately $17,800 \mathrm{t} \mathrm{SO}_{2}$.

\section{Revamp of a Kemira Ammonia Plant}

Kemira asked Belsim S.A. to help them to realise an ambitious project for the revamp of their ammonia plant in Tertre (BE), with the following objectives:

- To increase the capacity of the plant by X\% (X being non-disclosed at the request of Kemira).

- To decrease its specific consumption by $3 \mathrm{GJ} / \mathrm{t}$, in view of reducing energy cost and of meeting Kyoto recommendations.

A number of constraints were to be considered:

- The synthesis reactor loop was not to be modified,

- The furnace structure and the fumes fans were to be kept, thereby limiting the fumes rate to the current value,

- The specific consumption was to be kept within less than $1 \mathrm{GJ} / \mathrm{t}$ from the target value for a load varying between $85-100 \%$ of the new capacity of the plant.

To achieve these goals, a number of technologies and suggestions for improvement were to be considered, introduction of a pre-reformer and of a feed gas satu- ration system, decrease of the steam/carbon ration (S/C) or increase of the HP steam temperature.

The scope of the analysis was rather large, as those changes were to affect various parts of the plant. It was therefore necessary to analyse the complete plant as a single model:

- the reforming furnace, with its radiation and convection sections,

- the steam production and consumption,

- the production of the synthesis gas,

- the primary and secondary reformers,

- the shift conversion reactors,

- the $\mathrm{CO}_{2}$ removal,

- the synthesis loop,

- the refrigeration cycle.

On the other side, it was asked to take into account the effect of operating conditions, like the ambient temperature or the production level, on the plant performance. It was therefore necessary to have a sufficiently detailed model, accounting for the characteristic curves of the rotating machines or the effect of flow rates on the heat transfer coefficients.

The methodology used to tackle this problem (Fig. 5) has been based on two integrated tools:

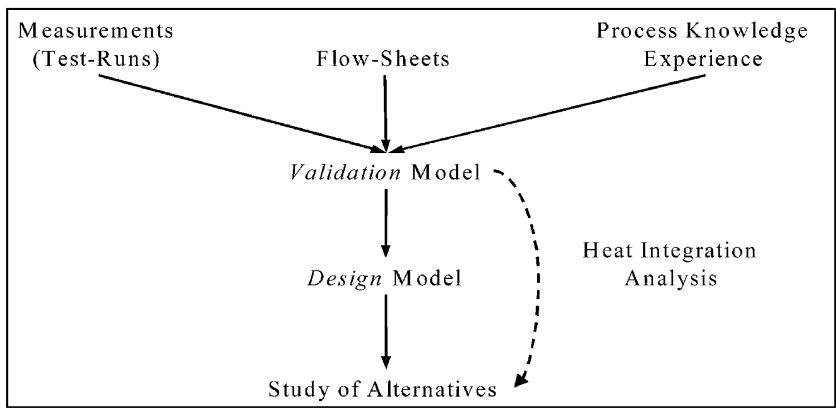

Fig. 5. Methodology. 
1. Flow-sheeting software VALI (equation solver based) for the validation of plant data, the modelling of the alternatives and the subsequent detailed and rigorous modelling of the revamped plant.

2. Energy integration analysis and synthesis package EASY.

A data validation model has first been developed to merge the information coming from test-runs data (3 test-runs at various loads were used), from the design flow-sheets and from the plant knowledge into a reliable model.

This validation step enabled them to:

- have complete and coherent heat and mass balances,

- identify Key Performance Indicators (KPI) such as turbine or compressor efficiency, heat transfer coefficient, distance from equilibrium in the reactors, deviations from the characteristic curves of the rotating machines,

- estimate the impact of selected KPI on the specific consumption $(\mathrm{GJ} / \mathrm{t})$.

On another hand, it has also enabled them to highlight the inaccuracy of some sensors. Some troubles due to vaporisation in the convection section of the furnace were also evidenced and quantified, in the current operation of plant.

Thanks to energy integration techniques, the model has been used to compute the Minimum of Energy Requirements (MER) and to locate the pinch point of the process. Results have shown that the actual energy consumption is close to the MER, indicating that the plant in its current configuration is well integrated.

In order to reach the target defined, further modifications of the process itself were necessary.

For the study of alternatives, the same model has been used in a different way. The (redundant) set of measurements has been replaced by a set of specifications. Inlet conditions and Key Performance Indicators (UA for heat exchangers, $\mathrm{DT}_{\mathrm{eq}}$ for reactors,...) identified during the validation phase have been specified in addition to the set of assumptions resulting from the alternatives to be considered.

The purposes of this study (increase of the plant capacity and reduction of the specific energy consumption) was to be achieved using the main alternatives proposed by Kemira:

- increase of HP steam temperature;

- reduction of S/C ratio;

- insertion of a pre-reformer;

- insertion of a "Feed Gas Saturation" system.

During this work it became clear that these alternatives were not leading to a solution meeting the objec- tives while satisfying the constraints of the revamped plant and of the inserted technologies. Additional modifications were therefore to be considered, which are not described here.

All along the revamp studies, energy analysis has been very helpful to confirm investigations made to insert new technologies (such as the Feed Gas Saturation system) and to verify the validity of the proposed revamp from an energy point of view.

Having reached the target in terms of energy consumption and capacity increase, the final flow-sheet and the list of modifications have been established (see Fig. 6 for the modifications required in the radiative and convective sections of the furnace).

The design model has been used to evaluate the impact of two major operating conditions on the specific consumption $\left(\mathrm{GJ} / \mathrm{t} \mathrm{NH}_{3}\right)$ :

1. Production level ranging from $85-100 \%$;

2. Ambient temperature.

Furthermore, a sensitivity analysis has been performed to identify the effect of parameters like turbine efficiency or HP steam temperature on the specific energy consumption.

\section{The insertion of new process(es) into existing production site}

The use of energy integration techniques as introduced by Linnhoff et al. [5] has been widely published to identify energy savings potential in industrial processes. The goal of such technology is to offer a graphical representation of the ideal but feasible heat exchange system to be envisaged for a given process. The Composite Curves like the Grand Composite Curve (Fig. 7) is a support for the creativity where engineers can identify not only the heat exchangers to install between hot and cold streams

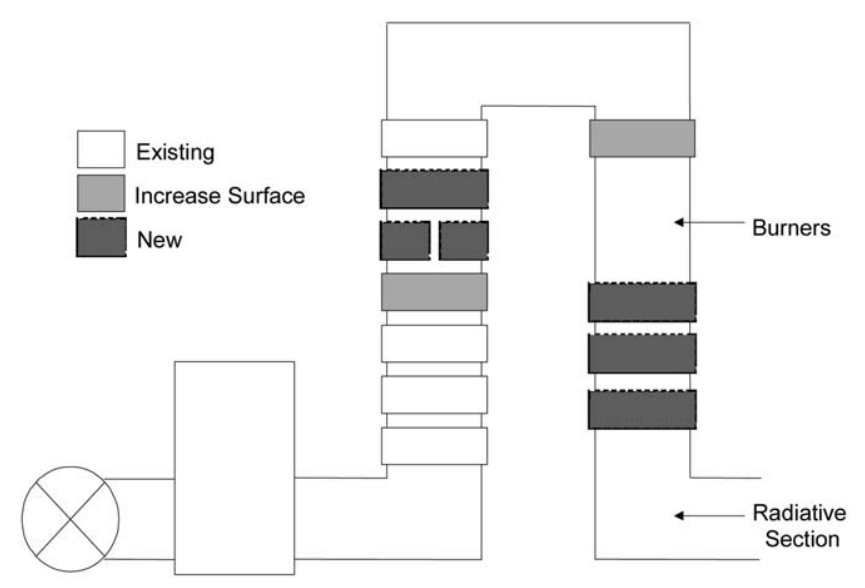

Fig. 6. Modifications in the radiation and convection sections of the furnace. 


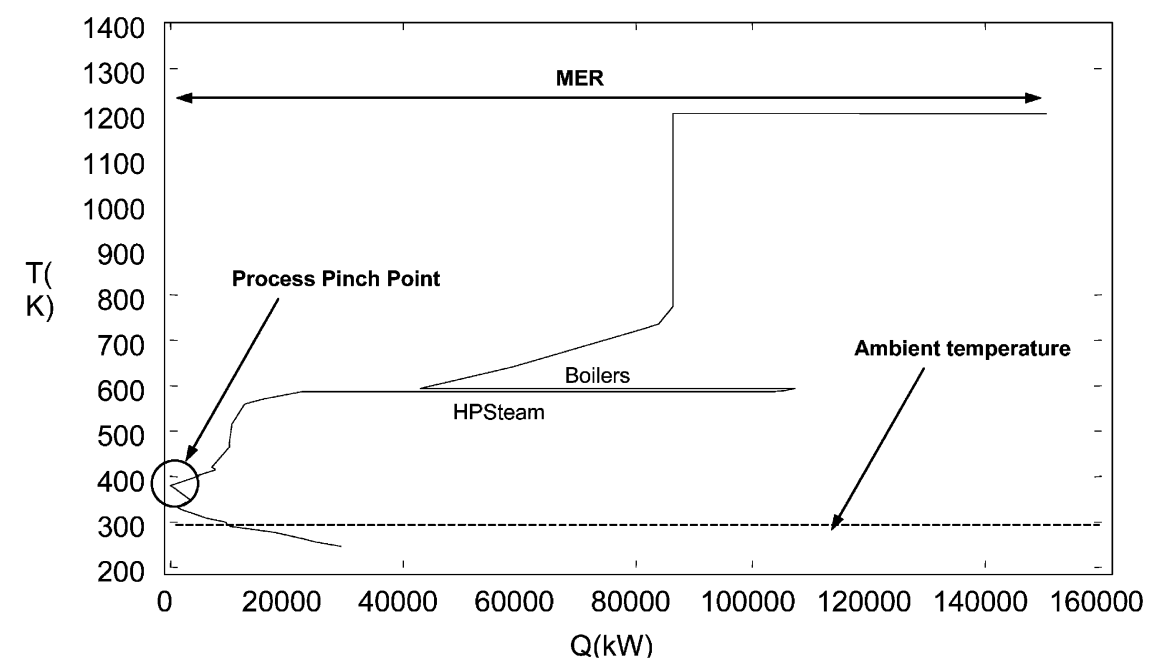

Fig. 7. Process system Grand Composite Curve to compute the minimum energy requirement of a process.

but also (and above all) actions to be taken to improve the energy efficiency of the overall system. The automated calculation of the composite curves using thermodynamic calculations and simulation results is of great interest to improve the engineer performance. Furthermore, combined with data reconciliation tools, the process integration techniques will play an evident role for retrofit studies.

On these curves, the temperature axis acts as a topological indicator allowing identification on a process flowsheet of the bottlenecking equipment, even for complex problems. The concepts of process integration stresses on the importance of adopting a global view considering the process as a whole. The natural evolution of the engineers has been to tackle not only heat recovery inside processes but also site wide process integration, considering total site envelop as the system to be analysed (Dhole and Linnhoff, [6] and Kalitventzeff and Marechal, [7]).

Fig. 8 shows the results of a study where a new process has been integrated into an existing production site. Without integration, the minimum energy requirement of the new process (process A) was of 3800 energy units (e.u.) while the minimum energy requirement of the existing site (Process B) was 4150 e.u. The integration of process $\mathrm{A}$ and $\mathrm{B}$ as visualised on Fig. 8 allows to compute a minimum energy requirement of 4600 e.u., leading therefore to an energy saving of $42 \%$ with respect to the non integrated solution.

The problem of the energy integration at a site level is the feasibility of the heat recovery exchange identified in the composite curves. The required heat exchanges are not always feasible in practice. In practice the steam network will play the role of energy carrier but raising at the same time the problem of combined heat and power production.

The practical application of energy integration tech- niques to actual industrial systems is in a dead-end if only energy is considered. The reason for this is the necessity of considering the heat recovery together with the integration of the technologies that transform the energy resources into process energy and distribute it to the processes to satisfy the energy requirements. Especially in the case of site wide integration, combined heat, power, combustion and steam networks come into play increasing the number of degrees of freedom of the system. The use of Mixed Integer Linear Programming (MILP) techniques allows passing through the dead-end and opens the possibility of analysing site wide integration. This technique has been described in Marechal and Kalitventzeff [8]). Once again, mathematical tools alone are not sufficient and graphical tools are needed to understand the integration and transform numerical results into solutions (Fig. 9).

The versatility and the adaptability of the MILP formulation allow simultaneous tackling of the problems of heat, power and energy resources and also allow to integrate the $3 \mathrm{E}-3 \mathrm{R}$ concepts by adding constraints and objective function terms related to the environmental impact (Marechal and Kalitventzeff [9]).

The use of optimisation techniques allows us not only to tackle the problems of energy savings or performance improvement but also to address the problems of operating flexibility or total cost optimisation. The true importance of this is revealed when combined heat and power solutions are studied. The importance of this approach is shown on Fig. 10 where combined heat and power solutions are tackled together with heat recovery using energy integration techniques. This figure presents three solutions, compared to the actual situation. The "cost of energy" is how much is to pay for satisfying the thermal energy requirement of the system studied; it can be reduced by $40 \%$ by energy integration. Without energy integration, the price of electricity makes the use 


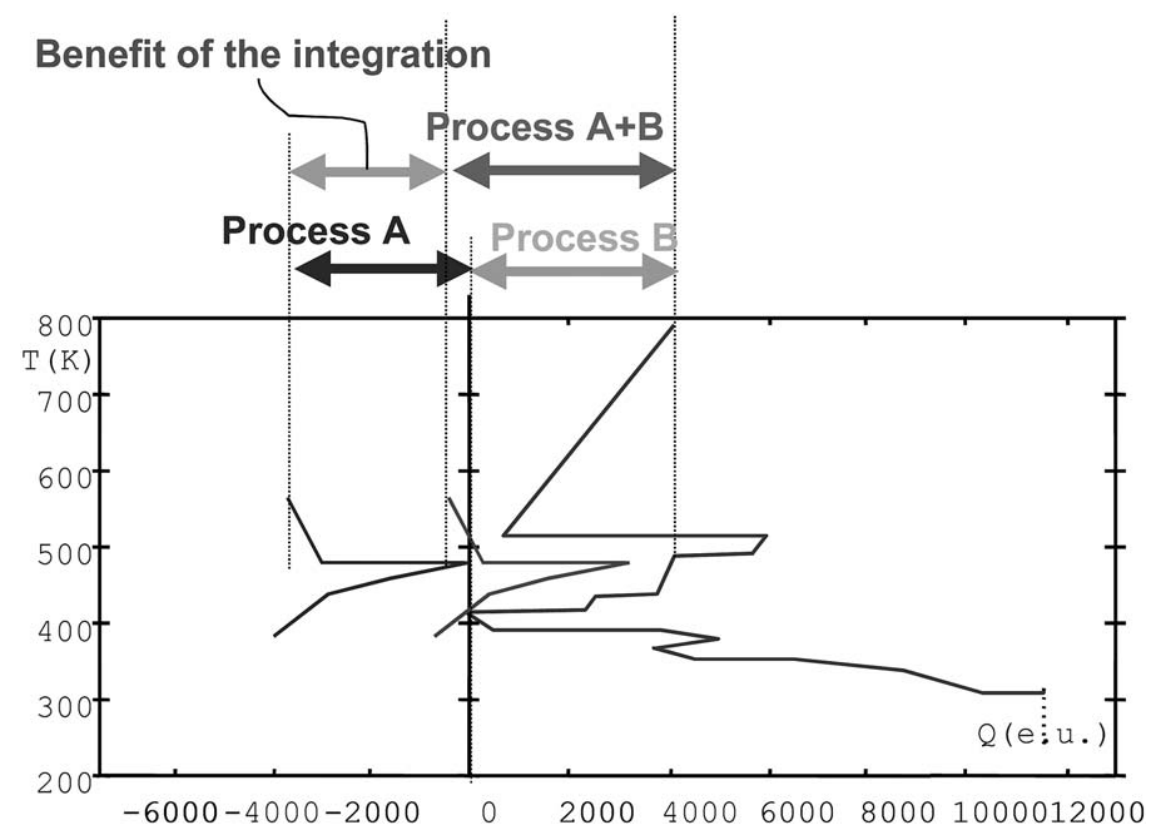

Fig. 8. Integration of a new process into an existing industrial site.

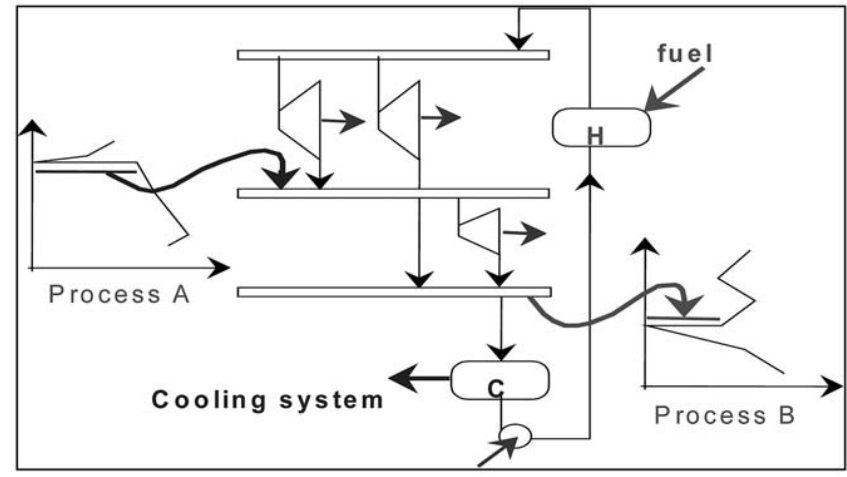

Fig. 9. The steam network as an energy carrier. of a gas turbine profitable, even more profitable than a solution with $40 \%$ of heat recovery but without a gas turbine. Energetically, the best solution is the integrated solution with combined heat and power production, but in this case the profitability of the integrated solution becomes lower than the profitability of the combined heat and power with a gas turbine alone.

This solution mainly depends on the relative prices of the investment, the fuel and the electricity.

Fig. 11 shows the impact of the electricity price on the value of the specific cost of the heat supplied to the process under study as a function of the thermal energy savings. This figure is a result of a study some of us did for the Belgian Ministry of Economic Affairs. It deals

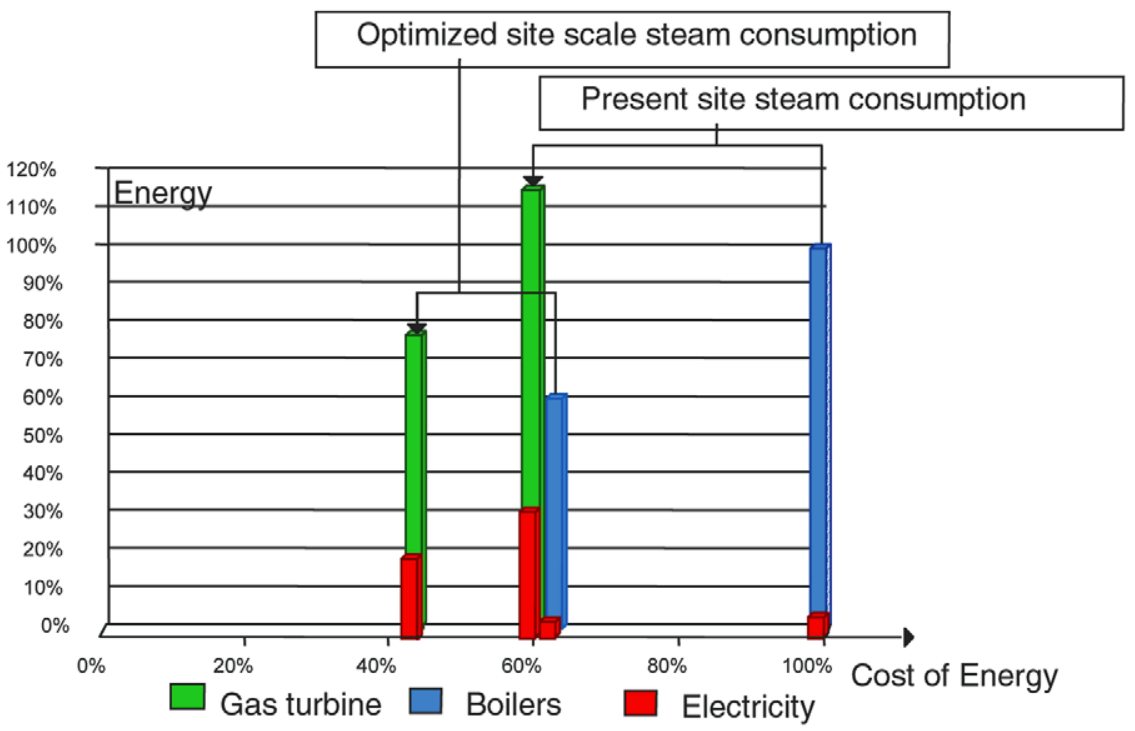

Fig. 10. Combined heat and power solutions. 


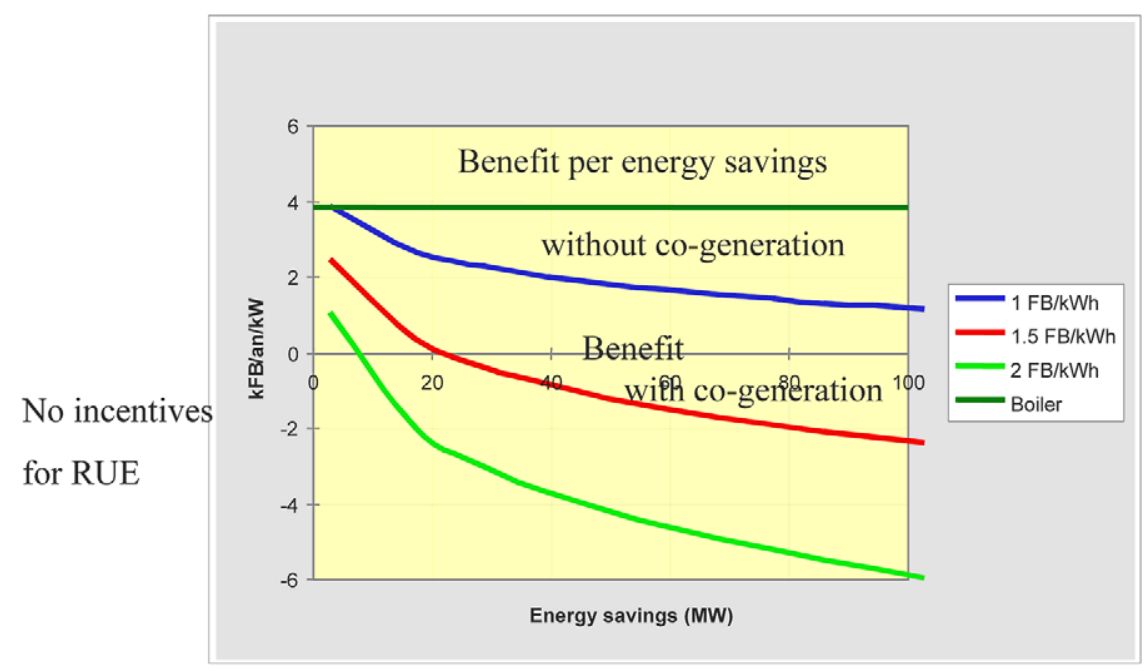

Fig. 11. Benefit from process thermal energy savings.

more specifically with the third E (Economics) that was mentioned here above. The ordinate indicates prices in $\mathrm{kFB} / \mathrm{an} / \mathrm{kW}$. Ordinate 4 corresponds to 0.10 kEuro per year per $\mathrm{kW}$. The reference horizontal line corresponds to the situation with energy savings only (no gas turbine), the specific benefit is constant. When energy savings increase, the combined heat and power production decreases and therefore the benefit of saving heat by integration decreases. There are therefore less incentives for reducing the heat requirements when combined heat and power is considered. In Fig. 11 we identify the break-even points that will cancel the incentive of reducing the thermal energy requirement according to the price of electricity. From a sustainable development point of view, is this showing good sense? Such a consideration indicates the difficulty of having a coherent energy market price basis.

\section{Conclusions}

Incentives exist for revisiting the structure of wellestablished plants in view of better process sustainability and economics. New tools exist to help the engineer in this task. The use of CAPE tools combined with an engineering approach in iterative three steps methodology (AGE) allows generating more sustainable processes with acceptable profitability. The benefit of using CAPE tools stands mainly in the fact that CAPE tools allow quick testing of ideas. The use of optimisation tools help engineers select between competing alternatives while graphical representation should help in sup- porting the creativity of engineers and understanding of the integration challenges of site wide industrial systems.

\section{References}

[1] Kalitventzeff B, Maréchal F. Optimal insertion of energy saving technologies in industrial processes: a web based tool helps in developments and coordination of a European R\&D project. Applied Thermal Engineering 2000;20:1347-64.

[2] Maréchal F. Méthode d'analyse et de synthèse energétiques des procédés Industriels. PhD Thesis. Edition de la Faculté des Sciences appliquées, $n^{\circ} 164$. Université of Liège, 1995.

[3] Dempf D, List T, Deinhammer W, Heyen G. Process for preparing 1,3-diketones, U.S. Patent ${ }^{\circ}$ US6310258 (Oct 30, 2001) (same as European patent EP1083162, March 14, 2001).

[4] Arpentinier P, Dumont MN. Maréchal F, Kalitventzeff B, Procédé et dispositif de production d'acide sulfurique. Brevet déposé au nom de l'Air Liquide, Société Anonyme pour l'étude et l'exploitation des procédés Georges Claude. Priority patent FR1998000009132, July 17, 1998, Docket nb S4591, 1998.

[5] Linnhoff B, Townsend DW, Boland P, Hewitt GF, Thomas BEA, Guy AR, Marsland RH. A user guide on process integration for the efficient use of energy. The Institution of Chemical Engineers, 1982.

[6] Dhole VR, Linnhoff B. Total site targets for fuel, co-generation, emissions, and cooling. Computers and Chemical Engineering 1992;17:s101-s9.

[7] Kalitventzeff B, Maréchal F. Process retrofit: Incentives for using Pinch technology concepts and adequate computer tools. 4th World congress of chemical engineering, STRATEGIES 2000, Karlsruhe (RFA) 1991; 16-21 June 1991: paper 8.4-2.

[8] Maréchal F, Kalitventzeff B. Energy integration of industrial sites: tools, methodology and applications. Applied Thermal Engineering 1998; 18:921-33.

[9] Maréchal F, Kalitventzeff B. Effect modelling and optimisation, a new methodology for combined energy and environment synthesis of industrial processes. Applied Thermal Engineering 1997;17:981-92. 